\title{
Origins and originators: Lesbian couples negotiating parental identities and sperm donor conception
}

Petra Nordqvist, University of Manchester

Petra.Nordqvist@Manchester.ac.uk

Post peer-review version of article published in

Nordqvist, P. (2012) 'Origins and originators: Lesbian couples negotiating parental identities and sperm donor conception', Culture, Health and Sexuality, 14(3): 297311.

DOI: $10.1080 / 13691058.2011 .639392$

Please refer to the published version for citations.

This article draws on Petra's $\mathrm{PhD}$ research into lesbian couples' experiences of donor conception. For more information about other articles published by Petra about lesbian donor conception and assisted reproduction more broadly, please visit http://www.manchester.ac.uk/research/petra.nordqvist/

Petra's most recent project 'Relative Strangers' (2010-2013) (with Carol Smart) explored the impact of donor conception on family life among heterosexual and lesbian couples. The research explored parents as well as grandparents' experiences of donor conception in their families. The findings from this project are available in the book 'Relative Strangers: Family Life, Genes and Donor Conception'. If you are interested in reading more about the project and see our videos, please visit http://www.socialsciences.manchester.ac.uk/morgancentre/our-research/kinship-andrelatedness/relative-strangers/ 


\title{
Origins and originators: Lesbian couples negotiating parental identities and sperm donor conception
}

\author{
Abstract \\ Donor conception challenges conventional kinship idioms: the involvement of a \\ gamete donor raises questions about parentage and also the meaning of genetic \\ heritage. Although there is now a growing body of literature exploring how people \\ resorting to donor conception negotiate kinship and connectedness, this \\ predominantly focuses on heterosexual couples. Little is yet known about how lesbian \\ couples navigate these processes. This paper builds on a qualitative interview study \\ comprising 25 lesbian couples in England and Wales with experiences of pursuing \\ donor conception in the context of their couple relationship to explore how these \\ couples negotiate the contribution of the donor. I explore how couples negotiate \\ meanings of parenthood, genetic origins, and the bodily process of conception. I argue \\ that lesbian couples negotiate parental identities, biogenetic relationships and also the \\ meaning of conception by disassembling and reassembling the meaning of kinship, \\ parenthood, creation, origin and originator. I suggest that lesbian couples weave \\ together old and new understandings of relatedness in complex patterns, and that this \\ enables them to assert authority as parents.
}

\section{Keywords}

Connectedness, donor insemination, genetic relatedness, kinship, lesbian, origin, parenthood 


\section{Introduction}

It is increasingly common that men and women resort to assisted reproductive technologies and conceive using donated gametes. In the UK, about 800 children are born from donor insemination every year and an additional 400 are born from egg donation (MacCallum 2009).

Donor conception challenges conventional kinship idioms and culturally prevailing understandings of conception, kinship, biogenetic connectedness and the beginnings of life. The involvement of a donor raises questions about who the parents are and also how to negotiate the meaning of genetic origins and heritage. Moreover, it raises questions about how to navigate the process of trying to conceive as this process is transported from the private sphere of the home into a public context involving another party. There is now a growing body of work exploring the impact of the new reproductive technologies on kinship and how individuals who resort to such technologies negotiate and understand genetic relatedness, family and parenthood (e.g. Becker 2000, Edwards 1998, 2000, Franklin 1997, Edwards and Strathern 2000, Strathern 1992, 1995, Thompson 2005).

Although the body of work in this area has expanded over the last decade, there is still a very limited knowledge about how lesbian couples pursue donor conception, and in particular how they navigate Euro-American kinship discourse as they conceive. To date, the work in this area has predominantly been concerned with the experience of heterosexual couples (see e.g. Becker 2000, Franklin 1997, Grace and Daniels 2007, Haimes 1992, Harrington, Becker and Nachtigall 2008, Strathern 1992, Thompson 2005). Little attention has been paid to the way in which lesbian couples negotiate using donated gametes (but see Hayden 1995, Luce 2010, Mamo 2007, Sullivan 2004 in a North American context).

In the UK a small body of literature exploring the lives of lesbian mothers has emerged however, this tends mainly to be located in debates about the changing formations of family and intimate life, situating lesbians' family formations in wider social transformations of intimate life. Investigating patterns of intimacy in late modern society, Weeks, Heaphy and Donovan (2001), for example, explore the possibilities and constrains felt by gay and lesbian parents and their families. The issue of 'fatherless families', motherhood, gender and 'good parenting' in the context 
of lesbian mothers has been a predominate focus of debate (Almack 2005, Donovan 2000, Dunne 2000, Gabb 2005, Haimes and Weiner 2000). In a similar vein, Almack (2008) explores the importance of family recognition and 'displaying family' in the lesbian mother family context, and Donovan and Wilson (2008) argue that the lesbian love relationship is central to lesbian couples' pursuits of parenthood. A small number of contributions situated within this body of work highlight how lesbian mothers negotiate the meaning of genetic parenthood, and how notions of kinship shape their family practices (Almack 2006, Donovan 2000, 2006, but note particularly Jones 2005). We have, therefore, a limited understanding of how lesbian couples may navigate Euro-American kinship as part of their conception process and also how such a discourse might shape their desires and practices.

This paper aims to bring lesbian couples' conception narratives in conversation with Euro-American kinship discourses utilising kinship as a framework to explore lesbian couples' experiences of trying to conceive. The article draws on empirical data and explores how lesbians negotiate the role and contribution of the donor. The article investigates how couples perceive the donor's role in relation to their definitions of parenthood; the issue of heritage and genetic origins; and also the involvement of a third party in the conception process. It demonstrates that lesbian conception is a meticulously managed process where aspects of parenthood, genetic roots and conception are carefully navigated. I put forward the argument that lesbian reproduction entails a careful and skilful negotiation of the cultural meaning of origin and originating and that this enables them to assert authority over the conception process and claim parental identities whilst also acknowledging the donor.

\section{Euro-American kinship discourse}

Euro-American kinship discourse is an important cultural interpretative resource in the context of assisted reproduction ${ }^{\mathrm{i}}$, and this paper is theoretically framed by critical engagements with such a discourse. Euro-American kinship idioms stipulate that individuals are interconnected as family and kin through either material substance (blood) or law (marriage) (Schneider ([1968] 1980, 37). Strathern notes that both substance and law relate to, and are shaped by, processes of procreation:

Persons we recognise as kin divide into those related by blood and those related by marriage, that is, the outcome of or in the prospect of procreation. (Strathern 1992: 16f.) 
Euro-American discourse is not, of course, at all neutral as to how procreation takes place, but centres on sexual procreation. Schneider ([1968] 1980) notes that commonsense discourse about procreation builds on the understanding that heterosexual intercourse defines family relationships, it 'stress[es] the sexual relationship between husband and wife and the biological identity between parent and child, and between siblings' (Ibid p. 51f). Commonsense understandings also hold that the relationship between the married couple, and between parents and their children, is that of love. This interlinks with culturally prevailing ideologies of marriage as symbolising love.

Heterosexual intercourse as method of conception is also linked to the type of connection that is perceived to exist between a child and her/his parents and between siblings. Carsten (2004) suggests that cultural depictions of the parent-child connection centres on an understanding that biogenetic substance is transferred from parents to child, and that this transference is perceived to constitute a bond of relatedness. Edwards (2000) indicates that such substance, located in gametes, is also perceived to contain and transfer passed relationships, and these are seen as important for the construction of identity. According to Nelkin $(2006,174)$, genetic substance is increasingly imagined to provide the essence of true personhood.

Charis Thompson (2005) argues that the transgressions of conventional kinship discourse posed by assisted donor conception are managed through a so-called 'ontological choreography' (Thompson 2005, 8). This depicts the process through which clinics and also parents negotiate assisted conception so that the intended parents are perceived as the parents of the conceived child (and not the egg, sperm or embryo donor). In particular, I utilise Thompson's suggestion that the alignment of things of different ontological orders is orchestrated through a process of disassembling and reassembling conception. This means foregrounding some aspects of parenthood (for example parental intention, gestation and birth) whilst marginalising others (for example, sexual conception, gametes and biogenetic linkages) (Thompson 2005, 145, 166).

\section{Lesbian donor conception in UK context}

A discourse of lesbians as unfit mothers strongly influenced UK legal and social discourse in the 1970s and the 1980s; lesbians were known to face court battles and 
would often loose custody over their children (Rights of Women 1984). This sentiment was echoed in regulation coming into force in the 1980s and 1990s. Section 28 of the UK Local Government Act 1988 banned the 'promotion of homosexuality' in schools, and created the idea of 'pretended family relationships' (Weeks, Heaphy and Donovan 2001, 158). At around the same time, licensed donor insemination treatment in clinics became regulated through the UK Human Fertilisation and Embryology Act 1990. This stated the need for licensed clinics to consider a 'child's need for a father' and thus curtailed lesbian couples' (and single women's) access to licensed clinics. Furthermore, it did not afford legal recognition of lesbian non-birth mothers.

In the last decade there has since been a radical change in attitudes and regulations governing gays' and lesbians' family life in the UK. Section 28 (above) was repealed in 2003. The Adoption and Children Act 2002 and the Civil Partnership Act 2004 made it possible for gay and lesbian couples to adopt and to register their partnership. The revised Human Fertilisation and Embryology Act 2008 replaced the clause of a child's 'need for a father' with 'supportive parenting' and also established routes to automatically secure the legal parenthood of lesbian non-birth mothers by establishing the possibility of two women being named on the birth certificate. After the Act came into law on 6 April 2009, the non-birth mother is automatically considered the legal parent of the conceived child if the couple are civil partners or have conceived in a licensed clinic. The situation is more complex for couples who conceive in private arrangements outside clinics (referred to here as self-arranged conception) and are not civil partners (Natalie Gamble Associates 2011)

With lesbians' access to clinics being legally restricted, self-arranged conception developed from the 1970s onwards as an established practice. With the restrictions now having eased, an increasing number of couples are accessing licensed donor insemination (Human Fertilisation and Embryology Authority 2006). However, this often becomes extremely costly and with access to clinics funded by the UK National Health Service uncertain, self-arranged conception remains a common route structured in part by classed subjectivities (Nordqvist 2011, Taylor 2009).

\section{The study}

The study comprised 25 qualitative in-depth interviews with lesbian couples in England and Wales, and fieldwork was conducted 2007-2008. As noted in previous 
studies of non-heterosexual intimate life, same-sex couples constitute a 'hidden' population and a hard-to-reach group; no sampling frame existed for their recruitment (Weeks, Heaphy and Donovan 2001). Random sampling was not an option, and so a purposive sampling method was employed. Lesbian couples were recruited using both online and offline gateways. Online recruitment primarily took place using message boards for gay and lesbian parents ${ }^{\mathrm{ii}}$, while offline gateways included 'snowballing' through personal and organisational networks and social events. It was difficult to know whether this study offered a representative cross-section of the UK population of lesbian couples, and this linked in with the constraints associated with sampling from a hidden population, the size of the study and recruitment method. However, themes that emerged from the interviews were likely to have generalisability beyond the sample, as the data offered in-depth understandings suggestive of the ways in which these processes are experienced by others (Franklin 1997).

I conducted semi-structured, theme-based narrative interviews that explored planning conception; doing the insemination; and becoming and being a family. Couple interviews were conducted where possible and altogether 45 women took part. All interviews were recorded and transcribed verbatim and the data were thematically analysed using a narrative-holistic approach (Lieblich, Tuval-Mashiach and Zilber 1998, 13). This was conducted using graphic elicitation and event-state networks which entailed constructing graphic 'maps' detailing the couples' routes to conception by marking events (e.g. met donor, visited clinic) and motivations (e.g. feelings, desires) that drove the events (Miles and Huberman 1994, 115f.). Codes and also themes were derived from the networks. The study design raised ethical issues around topic sensitivity and researcher's safety, and the study was ethically approved by the Centre for Women's Studies Ethics Committee, University of York. Names, places and identifying details in the interview extracts have been altered.

Twelve couples in the sample had pursued donor conception through a licensed clinic while eleven had undertaken self-arranged conception and a further two were planning future parenthood. The participants were between 23 and 56 years of age. Using highest educational qualification as an indication of social class (Graham 2007), one third of participants were from working class backgrounds and two thirds were from middle class backgrounds. Forty two women defined as white British, Welsh or English and three women identified as of mixed ethnic origin, Chinese British and Black British. 


\section{Pathways to parenthood}

\section{Defining parenthood}

Perhaps the major question for lesbian couples who pursue conception, and one with strong kinship associations, is how to negotiate the donor's position as a potential parent (Donovan 2000, Luce 2010, Ryan-Flood 2009, Sullivan 2004). As with previous studies, I found that the women's visions about parenthood would shape their decisions regarding known or anonymous donors. Most couples wanted anonymous donors, but some wanted donors who would be known to the child in an 'uncle' capacity; others wanted donors who would be involved in the upbringing of the child.

Similarly to Donovan and Wilson $(2008,656)$ I found that the decision against known donors was motivated by a vision of family based around joint parenting. The couples also experienced a known donor and a natural legal father as a potential threat to the already uncertain position (legally but also socially) of the non-birth mother (Nordqvist forthcoming $a$ ). Donor anonymity was only fully realisable in reproductive health centres, and most commonly the women expressing a desire for unknown donors sought access to health centres to conceive. ${ }^{\text {iii }}$ But also couples who selfarranged conception expressed desires for 'anonymous' relationships with donors, notwithstanding that anonymity was not fully realisably in this context. ${ }^{\text {iv }}$ Frances' account was typical:

I didn't want to have to consider there being a third parent in the family really, which would kind of maybe be the case with using a known donor. Yeah, I don't feel the need to share [our child] with another parent. So we decided, yeah, the two of us were enough so, yeah, we would use an anonymous donor; and that was that. (Frances, clinical conception)

Frances (and her partner) were in favour of the donor anonymity regulation in place in the health centre, and taking this route enabled them to detach the donor from any parental role. Frances did not want to 'share' any conceived child with a third parent. Put slightly differently, she was not willing to let the donor have a 'share' in the child. As such, the account suggests a sense of ownership in the child; and a child-centred view of reproduction and parenting as stimulating the couple's desires (Beck and Beck-Gernsheim 1995,105, 129). The view of parenthood emerging from accounts such as this illustrates a form of instrumental intimacy which centres on the couple, 
their desires and emotional needs, thus bringing to mind Gabb's $(2010,109,166)$ suggestion that parent-child affective practices have instrumental elements (and are not merely altruistic). The instrumentality emerging here might be viewed as a 'contractual intimacy' in the sense that the couples strategically negotiate who, out of the people who contributed to the conception, could have 'ownership' in the child, should be allowed to bring him or her up as their own. This way of contracting intimate relations echoes Luce's (2010) notion of 'contracting kinship'. The contract of intimacy emerging here affords parenthood to the dyadic couple, seeing the couple as the foundation of the family (see also Ribbens McCarthy, Edwards and Gillies 2003). Given the social context of lesbian parenthood, and the potential threats of a known donor, this also signals how couples work to underpin and future proof their position as parents. What emerges are understandings of parenthood that centres on ownership and control, and following Euro-American kinship discourse it centres on the couple relationship and love, affording parental privilege to the dyadic couple.

Interestingly, this definition of parenthood also emerged in the accounts of couples who had known donors. Knowing the donor did not necessarily bring with it a different view of parenthood, nor did it mean that couples and donors 'shared' parenthood equally. Six couples pursued conception using donors who were known as 'uncles'. Many of these couples expressed a belief that it would be important for the child to know the donor as he/she grew up. Although these couples sought to construct a familial relationship between the child and the donor, this was carefully distinguished from a parent-child relationship. Lisa and her partner pursued selfarranged conception with an identifiable donor:

We knew that if it was going to be a friend we'd want him to be known as the donor, as a kind of uncle figure, so part of the extended family, but not a parent. We've always wanted to just be the parents ourselves, we wanted to maintain the control. (Lisa)

A similar focus on the couple relationship and strategic management of parental identities emerged from the accounts of couples with involved donor fathers. Wendy and Penny, for example, had a child with a friend and active father. But although the donor was involved in bringing up the child, he did not have the same parental role as the couple. This was illustrated in the couple's account about contracting the relationship (Luce 2010) with the donor before the insemination process commenced: 
Wendy [W]e drew something up which we wrote and that he and we signed. Which sort of... basically went through the fact that he would be the donor father. That Penny and I would be...

Penny The day to day parents.

Wendy The full time parents. [...] We would be responsible for the day to day decisions regarding healthcare, schooling, routines, all the things that parents make decisions about. Choosing names.

Penny We would discuss stuff with him and we would try and come to agreement if there were areas of difference. But that ultimately, if there was an area of difference, and that a decision had to be made, that we would be the ones making that decision.

Wendy and Penny defined parenthood in terms of care and financial responsibility, thus constructing an understanding of parenthood based on an 'ethics of care' (Smart and Neale 1999). In this case, the donor was legally a parent whilst Penny (the nonbirth mother) was not, and so there were obvious threats to the couple's definition of parenthood. But Wendy and Penny carefully made explicit the kin relationships and parental connections in their arrangement. Following Thompson, $(2005,148)$ seeking to define the parental positions involved, and the different level of significance of these relationships, represented a way of managing the threat, and ambiguity, posed by the donor father. Although the donor was considered a father, the perceived primary parenthood was located in the lesbian couple. No couple in my study with a known donor father saw him as an equal parent.

Although the couples in my study had chosen different ways of relating to the donor, what emerged across the narratives was a location of primary parental identities in the lesbian love relationship. Similarly to Donovan and Wilson (2008, 662), I found that the couples regarded the fact that they were two parents as the defining feature of their family. My data highlight that it is not only couples who conceive in health centre, but also couples who self-arrange conception and involve donors as fathers, who perceive the dyadic parenthood relationship as the defining feature of their family.

The couples' accounts carefully balance kinship values such as the couple relationship being the bases of parenthood, with love, intimacy, responsibility and knowing one's origins. The construction of parenthood that emerges sidelines 
heterosexuality, fatherhood and biogenetic links whilst emphasising parenthood as a dyadic project, confined to the loving couple and as based on ethics of care, love, intention and financial responsibility. Drawing on Thompson $(2005,145)$, the women pick apart cultural notions of what makes a parent and reassemble a selection of cultural definitions. The women link their parental project to some extent to conventional family discourse, and this enables them to call the child their own. Although these conception practices might be unusual, what emerges is an understanding of parenthood that strongly connects with conventional kinship discourse.

\section{The meaning of genetic origins}

It might be expected that lesbian couples who define parenthood primarily as care would overlook the issue of genetic origins and biogenetic parentage in the donor. However, my interviews suggested that the women navigated notions of care and biogenetic linkages in quite complex ways.

Although all of the couples identified themselves as parents, many cherished the idea that knowing about one's genetic background, or being able to access such information, could be both meaningful and important for the child (see also Almack 2006, Hayden 1995). Strathern (2005) notes that kinship as a concept combines interpersonal and conceptual (biogenetic) dimensions. This combination emerged in the interview accounts, with the split between the two enabling the couples to construct a notion of parenthood as based on relationality whilst also recognising the donor's genetic contribution. Although donors were not seen as parents, they were often perceived as having important conceptual value, thus reflecting Donovan's (2006) suggestion that a growing importance is given to genetic fatherhood in the UK.

Lisa and her partner, with many others, started their journey to conceive when donors in British clinics were fully anonymous. Their decision to self-arrange conception was shaped by their desire to have an identifiable donor. Lisa said:

We knew that if we went through a clinic it would be with anonymous sperm that would never be traceable and neither of us felt comfortable with that. [...] It might not be an important part of our family, but it's a part of our heritage.

Interestingly, Lisa distinguished between 'family' and 'heritage', concepts that are conventionally conceptually entangled. By disentangling interpersonal and conceptual 
kinship dimensions, she overlooked the social relationship between child and donor whilst acknowledging their genetic relationship.

My study indicated that the couples associated donor identification and genetic linkages with being able to provide the child with an answer to the question 'where do I come from'. This led many to refrain from seeking conception in reproductive health clinics prior to 2005 (Jean, below), and also from importing non-identifiable donor sperm (Carol, below).

We wanted a known donor who would have a role in the child's life but not a parental role 'cause I think we thought at that stage that it was really important for the child to know the extent of its genetic make-up and to be able to look at somebody and say, oh, okay, that's where the other half of me comes from but that we were definitely the parents. (Jean)

I would hate one day to have to explain to my little girl, where do I come from mummy? Well, you come from Sperm Direct.com. I couldn't... I'd hate to have to do that. (Carol)

According to Edwards (2000, 228), anxieties around anonymous gamete donations are associated with perceptions that children require knowledge of their genetic roots. Not knowing one's origin is culturally associated with being disconnected from people, both in the past and present, and it is culturally perceived as leaving the child unprotected (Edwards 2000, 229). Knowing one's genetic parentage is culturally understood to provide 'constitutive information' of a person's sense of self (Strathern 1999, 68) and Carol's objection to the online purchase of sperm is shaped by the idea that knowing one's roots has implications for the construction of personal identity. Just as an adopted child's search for its birth parent can be experienced as a route to discover a missing sense of self (Carsten 2004, 104), the couples considered donors to have a knowledge-constitutive value in that they could contribute to the child's future sense of self. Edwards $(2000,233)$ demonstrates that gametes need to be linked to names, which attach them to origins. As such, self and origin are constructed in relation to the past (Edwards 2000, 231). In my study, both couples who went to clinics and who conceived privately, and regardless of whether they had involved donors or not, believed that it could be important for the child to know her/his biogenetic origins. Following Almack $(2006,10)$, securing such knowledge was framed as meeting the child's need. 
It might appear that such knowledge would be best ensured through a known donor. A family member might be the ideal donor for providing constitutive genetic knowledge. Indeed, many in the study had considered asking a family member to donate. Sophie and Lizzie, who were expecting their first child with Sophie as birth mother, had considered asking Lizzie's brother to donate:

Sophie 'Cause then we'd have like the genes, the... you know...

Lizzie A genetic link from me as well. Not that that's important to me but it was free [laughter] for a start and we knew the donor and we knew the background.

Sophie And he would be involved in things like that but in the back of our minds we also wondered if it might be that he might look at our child was more his... [...] A bit more of a claim on it than Lizzie, you know, just a bio...

Lizzie It was too close, that was the problem. And it's not like you could... he could donate and walk off type of thing. And not that we were like, you know, we can't share but it was just too messy, wasn't it?

Lizzie and Sophie's account demonstrates how conflicting cultural perspectives of kin connectedness came into play as they evaluated the kin value of the donor. The couple noted how Lizzie's brother provided a genetic connection between Lizzy (the nonbirth mother) and the child, and in that sense they considered him an ideal donor. In a Euro-American kinship system, siblings are perceived to share genetic substance and in donor conception, siblings are often seen as providing a genetic link between the child and the non-genetic parent (Thompson 2005). Through her brother's donation, Lizzie would become genetically connected to the baby. Furthermore, he was well known to the couple and so they trusted him. However, at the same time these reasons meant that his involvement was considered too close: the couple feared that he might have more claim to the baby than Lizzie would do. Again, the term 'share' highlights the couples' sense of ownership in the child and an unwillingness for anyone else to claim the child for their own. Strathern $(1995,347)$ suggests that a known genetic connection is irreversible. The brother, because of his status as such, could never become 'unknown' as the child's genetic source. Because of his connection as family 
he could not 'walk off'. Furthermore, he was connected and 'to be connected and not to be able to claim connection is problematic' (Edwards 2000, 224).

A sibling donor was therefore perceived as a risky choice because it was someone who might disrupt the carefully crafted parental identities (Edwards 1998, 163). Edwards $(2000,224)$ indicates that the transference of donated gametes is conceptualised through already existing relationships. With a known donor, the couple would be less able to disassemble genetic relatedness from parenthood. Wanting to construct themselves as the parents, such fluidity and complexity was not tolerated. The donor's genetic and interpersonal connection to the non-birth mother therefore rendered him unsuitable. Couples like Lizzy and Sophie would often therefore refrain from asking family members for donations.

What emerges from the data was thus a complex interplay between genetic heritage, family boundaries and parental authority. Genetic origins were constructed as a property in the person, but not as a property integral to parenthood. The donor had a conceptual value, but only insofar as the information could be made available at $a$ later stage and only as long as it did not threaten the parental authority of the lesbian couple. In the end, Sophie and Lizzy went to a sperm bank. Sophie explained:

I think I quite like the idea of... that the child will be our child and will be brought up our way and nobody else will interfere with it [...] But I love the idea that at 18 it can find out [...] The sperm comes from a bloke in America and as far as we're concerned, we haven't really discussed it, but I think we're probably both happy with the fact that when the child is $18-$ if he or she wants to - we would probably be funding and going to America with him or her to try and find out and stuff.

A personal relationship with the donor established at the age of 18 was not perceived to threaten the mothers' status as parents. At that stage it had become safe, and was limited to providing information about who contributed to the child's body (Strathern 1999, 76). Sophie's account display a strong claim on the child, and also a powerful role in guarding any information the child will be given about the donor. Through disassembling and reassembling competing kin concepts of care, connections and genes, the couples' asserted their claims to parenthood. 


\section{Organising conception}

The involvement of a donor posed further dilemmas in terms of the method of conception. Schneider ([1968]1980) highlights that heterosexual intercourse is central to Euro-American kinship discourse. The lesbian couples in my study were faced with the challenge of how to assert their joint parenthood despite not being able to conceive sexually. Processes of insemination/in vitro fertilisation (IVF) had to be managed to 'contain' the necessary other party (the clinic/staff/donor).

The women who self-arrange conception could not rely on the clinic to organise an anonymous handover of sperm, but had to organise retrieving the donation, and do the insemination, themselves. These couples emphasised that it was important that they alone undertook the insemination. No couple in my study conceived using sexual intercourse with the donor. Sue indicated that sexual intercourse would violate their relationship, an account typical among my interviewees:

[T] o me, no one else is touching [my partner], whether it's to try for a baby or not, to me it's inviting a third person into that relationship, isn't it?

The couples' narratives also indicated that a donor being present at the time of (artificial) insemination would overstep couple boundaries. Juliet and Harriet attempted to conceive in self-arranged conception and travelled to see the donor with the assumptions that the donor would leave a donation with them, and then depart. The donor, to their shock and devastation, however, insisted that he should do the insemination. Harriet said:

Because he was a medical doctor he insisted on doing the insemination himself which shocked me, so much so I couldn't say anything else and so it was kind of, as soon as he was in the room it was like, I'm really not comfortable with this. [...] It's got to be one of the worst experiences of my life and I was thinking, this is not the way I want to have a child.

This account indicates how carefully the couples sought to orchestrate the insemination in a way that excluded the donor from the insemination process. The couple experienced the donor's overstepping of intimate boundaries as a profound violation of their relationship and also their vision of conception. It also indicates how situations such as this can make couples vulnerable to abuse. 
The accounts indicate that the lesbian couple relationship had to take central stage in the conception process for it to be experienced as positive. Donors were, for example, excluded, and the process of retrieving a donation carefully managed (Nordqvist forthcoming $b$ ). It was not seen as suitable that the birth mother would receive treatment/donor sperm on her own, although this might sometimes have been more practical. Although the couples did not associate insemination with sex, it nevertheless represented a moment charged with emotions and visions of a joint future. Pippa recalls her and her partner's first insemination attempt:

You know we were just lying in bed and we just like, wow you know we could have just done it. And then, it was quite emotional and tears.

The couples in my study had often planned how to conceive for many years, and many had also pursued various lengthy arrangements with donors that had fallen through (see also Donovan and Wilson 2008, Dunne 2000), which added emotional charge to the process.

Also couples who had tried to conceive for some time, perceived the insemination to be a marker of the couple relationship. Emily and Poppy attempted to conceive over a period of two years. Every month they mapped ovulation and met up the donor to retrieve a donation. They started off by self-arranging conception, but when the arrangement with the donor fell through, they turned to a clinic for intra-uterine insemination (IUI). Like other couples in my study, Emily and Poppy experienced that trying to conceive was hard work, and that it was difficult to maintain a level of romance and emotional investment as time went by. Typically, the euphoria expressed in Pippa's account (above) would over time turn into a more instrumental approach to the process as the couples would begin to feel the stress involved in arranging donation/insemination every month. However, Emily stated that although they no longer perceived the insemination as romantic, she and her partner Poppy would 'do something nice' together:

I [do] try and make sure that we have... you know, if we can we have the rest of the day together and we go and do something nice, you know, we don't go to work, we go shopping. In fact, the last time we went to Ikea afterwards and got some things for the house, you know, that sort of thing. 
Many also stated that they found it important that the non-conceiving partner was actively involved and present at the moment of conception. Poppy, Emily's partner, was, for example, adamant that she should 'do' the insemination:

Interviewer Are there ways that you take part in Emily getting pregnant, that you feel are important to you? She was mentioning you both going to the clinic.

Poppy Yes. I have to press the plunger! [...]

Interviewer How does that feel important to you? [...]

Poppy It feels important to me because it means that symbolically I am making Emily pregnant, by doing the insemination [...] Its tokenistic but its important to me. I also look after her as much as I can.

Interviewer Yeah. How do you mean tokenistic?

Poppy 'Cause well I don't have sperm - I am just helping it on its way.

By 'pressing the plunger' Poppy took a central part in the conception process. It made her actively involved in making the baby. Poppy also said that she looked after Emily, thus linking understandings of 'having sperm' with the dyadic couple relationship, intimacy, love and care. The process was carefully managed to allow the non-birth mother to connect with and become linked to the conception process and the baby. The way in which she constructed meaning in 'pressing the plunger' is culturally intelligible because it draws on Euro-American kinship discourse which links together heterosexual intercourse, love, couple relationship and parenthood.

My data indicate that the couples undertook insemination in ways that emphasised the couple relationship, whilst carefully navigating the donor, and the sperm, in the process. The final quote illustrates particularly well the separation between couple and donor, and the varied importance afforded to each party. Sue and Trish recall considering the possibility of Trish doing the insemination on her own:

Trish It's not right that we should do it if you're not there, because the whole point is that we are creating a child.

Sue In our minds we are.

Trish In our minds that's what we are doing, we are creating a child. The fact that there's this outside source that we have to go to as an ingredient ...

Sue It's us that's making the cake. 
Trish Yes, we are the ones who are making the child.

Drawing on Thompson (2005) the couples disassembled conception into its separate parts and reassembled it in ways that allowed the couple unit to take centre-stage in the process. The couples thus utilised dimensions of conventional kinship and family discourse, but only insofar as it allowed them to assert ownership over the conception process.

\section{Discussion}

This article has brought lesbian couples narratives of pursuing parenthood using donor sperm in the UK in conversation with Euro-American kinship discourse. It has explored how such a conceptual framework can provide a framework for investigating the complex negotiations of parenthood, kinship, origins and conception that characterise these parental pursuits.

Both old and new understandings of intimacy, procreation and parenthood come together in multilayered ways in these unusual accounts of pursuing parenthood. The data that I draw on highlight how couples' carefully manage the contribution of sperm donors by disassembling and reassembling conceptual, practical and intimate dimensions of reproduction and Euro-American kinship discourse. Culturally interconnected aspects of parenthood such as gender, heterosexuality, connectedness, genetic origins, and heterosexual intercourse were separated out and managed individually, bringing to mind Thompson's (2005) work on 'ontological choreography'. While parental love, intimacy, care, intent and agency were emphasised, biogenetic relatedness, genetic origins and sexual intercourse were marginalised. Aspects of procreation were moved around, separated or merged (Franklin 2003), enabling lesbian couples to assert parental authority and claim the child they hoped to conceive as their own.

I argue that the process through which lesbian couples were able to do so can be characterised as a procedure of disentangling the meaning of origins from the meaning of originator in the context of procreation. The interviewees uncoupled wanting to have children in the context of their relationship, from producing the sperm necessary to make this happen. The donor was acknowledged as an important contributor, but his contribution was carefully managed and only valued and recognised as a detail in the process (Konrad 2005). It was the lesbian couples' 
intention to create a child that drove the process and it was that intention that allowed them to position themselves as the originators of the child and lay down claims to parenthood. By undertaking the process in carefully structured ways that emphasised the lesbian love relationship, couples would define themselves as the originators and creators of the process of conception.

By exploring accounts of genetic heritage and conception manoeuvres my data highlight how the emerging importance of genetics (Nelkin 2006) is given meaning among lesbian couples, shaping their routes to conception. This emphasis on genetic inheritance, however, sits alongside an emphasis on the dyadic couple relationship as the foundation of family life. Importantly, there is a notable lack of emphasis on the fathers having a social roles in families recorded in previous work in the UK (i.e. Donovan 2000, Haimes and Weiner 2000), suggesting an uncoupling of 'doing' fatherhood and genetic heritage. The data also suggest that the conception process itself, and the way that donors and sperm are managed as part of that, carry meaning for asserting parental authority, thus adding complexities to gendered accounts of conception and parenthood.

This article has explored how lesbian mothers negotiate the genetic relationship between the donor and the child. But this is not the only relationship that is likely to give rise to negotiations around the role of genetic relatedness in these families. The way in which the women negotiate biogenetic connectedness between themselves as birth and non-birth mother (Almack 2005, Gabb 2005 and Jones 2005), and with their extended families, is likely to add further layers of complexities to the argument presented here. Exploring such issue would be an important question for future research.

\section{Acknowledgements}

This research was supported by the Economic and Social Research Council Doctoral Award (ref. PTA-031-2006-00503), Funds for Women Graduates and British Sociological Association Support Fund. Thanks to the women who agreed to take part in my research and make this study possible. Thanks also to the anonymous reviewers for very helpful and insightful comments and suggestions on this paper. I am also grateful to Professor Carol Smart for comments on previous drafts of this article. 


\section{References}

Almack, Kathryn. 2005. What's in a name? The significance of the choice of surnames given to children born within lesbian-parent families. Sexualities $8(2): 239-254$.

Almack, Kathryn. 2006. Seeking sperm: Accounts of lesbian couples' reproductive decision-making and understandings of the needs of the child. International Journal of Law, Policy and Family 20(1):1-22.

Almack, Kathryn. 2008. Display work: Lesbian parent couples and their families of origin negotiating new kin relationships. Sociology 42(6):1183-1199.

Beck, Ulrich and Elizabeth Beck-Gernsheim. 1995. The Normal Chaos of Love. Cambridge: Polity Press.

Becker, Gay. 2000. The Elusive Embryo. How Women and Men Approach New Reproductive Technologies. Berkeley: University of California Press.

Carsten, Janet. 2004. After Kinship. Cambridge: Cambridge University Press.

Donovan, Catherine. 2000. Who needs a father? Negotiating biological fatherhood in British lesbian families using self-insemination. Sexualities 3(2):149-164.

Donovan, Catherine. 2006. Genetics, fathers and families: Exploring the implications of changing the law in favour of identifying sperm donors. Social \& Legal Studies, 15(4): 494-510.

Donovan, Catherine and Angelia R. Wilson. 2008. Imagination and integrity: Decision-making among lesbian couples to use medically provided donor insemination. Culture, Health and Sexuality 10(7):649-665.

Dunne, Gillian A. 2000. Opting into motherhood: Lesbians blurring the boundaries and transforming the meaning of parenthood and kinship. Gender and Society 14(1):11-35.

Edwards, Jeanette. 1998. Donor insemination and 'public opinion'. In Donor Insemination: International Social Science Perspectives, edited by Ken Daniels and Erica Haimes, 151-172. Cambridge: Cambridge University Press.

Edwards, Jeanette. 2000. Born and Bred: Idioms of Kinship and New Reproductive Technologies in England. Oxford: Oxford University Press.

Edwards, Jeanette and Marilyn Strathern. 2000. Including our own. In Cultures of Relatedness. New Approaches to the Study of Kinship, edited by Janet Carsten, 149-166. Cambridge, Cambridge University Press. 
Franklin, Sarah. 1997. Embodied Progress. A Cultural Account of Assisted Conception. London: Routledge.

Franklin, Sarah. 2003. Rethinking nature-culture: Anthropology and the new genetics. Anthropological Theory 3:65-85.

Gabb, Jacqui. 2005. Lesbian m/otherhood: Strategies of familial-linguistic management in lesbian parent families. Sociology 39(4):585-603.

Gabb, Jacqui. 2010. Researching Intimacy in Families. Basingstoke: Palgrave Macmillan.

Grace, Victoria M. and Ken R. Daniels. 2007. The (ir)relevance of genetics: engendering parallel worlds of procreation and reproduction. Sociology of Health \& Illness 29(5):692-710

Graham, Hilary. 2007. Unequal Lives: Health and Socio-Economic Inequalities. Maidenhead: Open University Press.

Haimes, Erica. 1992. Gamete donation and the social management of genetic origins. In Changing Human Reproduction. Social Science Perspectives edited by Meg Stacey, 119-147. London: Sage.

Haimes, Erica and Kate Weiner. 2000. 'Everybody's got a dad...'. Issues for lesbian families in the management of donor insemination. Sociology of Health and Illness 22(4):477-499.

Harrington, Jennifer, Gay Becker and Robert Nachtigall. 2008. Nonreproductive technologies: Remediating kin structures in donor gametes. Science, Technology and Human Values 33(3):393-418.

Hayden, Corinne P. 1995. Gender, genetics and generation: Reformulating biology in lesbian kinship. Cultural Anthropology 10(1):41-63.

Human Fertilisation and Embryology Authority (2006) Figures for treatment of single women and lesbian couples 2000-2005. Accessed 31 October 2006. http://www.hfea.gov.uk/cps/rde/xchg/hfea.

Jones, Caroline. 2005. Looking like a family: Negotiating bio-genetic continuity in British lesbian families using licensed donor insemination. Sexulities 8(2):221237.

Konrad, Monica. 2005 Nameless Relations. Anonymity, Melanesia and Reproductive Gift Exchange between British Ova Donors and Recipients. Oxford: Berghahn Books. 
Lieblich, Amia, Tuval-Mashiach, Rivka and Tamar Zilber. 1998. Narrative Research. Reading, Analysis and Interpretation. London: Sage.

Luce, Jacuelyne. 2010. Beyond Expectation. Lesbian/Bi/Queer Women and Assisted Conception. Toronto: University of Toronto Press.

MacCallum, Fiona. 2009. Embryo donation parents' attitudes to donors: comparison with adoption. Human Reproduction 24(3):517-523.

Mamo, Laura. 2007. Queering Reproduction: Achieving Pregnancy in the age of Technoscience. Durham: Duke University Press.

Miles, Matthew B. and A. Michael Huberman. 1994. Qualitative Data Analysis. An Expanded Sourcebook. $2^{\text {nd }}$ ed. London: Sage Publications.

Natalie Gamble Associates. 2011. Donor conception and co-parenting law pages. Accessed 23 June 2011. http://www.nataliegambleassociates.co.uk.

Nelkin, Dorothy. 2006. Gene as a cultural icon. In Living with the Genome, edited by Angus Clarke and Flo Ticehurst, 171-176. Basingstoke: Palgrave Macmillan.

Nordqvist, Petra. 2011. Dealing with sperm: Comparing lesbians' clinical and nonclinical donor conception processes. Sociology of Health and Illness, 33(1): 114129.

Nordqvist, Petra. Forthcoming a. "I Don't Want Us to Stand Out More than We Already Do': Complexities and Negotiations in Lesbian Couples' Accounts of Becoming a Family through Donor Conception', Sexualities.

Nordqvist, Petra. Forthcoming $b$. 'Choreographies of Sperm Donations: Intimacy and Distance in Lesbian Couple Donor Conception', Social Science and Medicine.

Ribbens McCarthy, Jane, Edwards, Rosalind and Val Gillies. 2003. Making Families. Moral Tales of Parenting and Step-Parenting. York: sociologypress.

Rights of Women. 1984. Lesbian Mothers on Trial. A Report On Lesbian Mothers and Child Custody. London: Rights of Women.

Schneider, David M. [1968] 1980. American Kinship: A Cultural Account. $2^{\text {nd }}$ ed. Chicago: The University of Chicago Press.

Smart, Carol and Bren Neale. 1999. Family Fragments? Cambridge: Polity Press. Strathern, Marilyn. 1992. Reproducing the Future. Essays on Anthropology, Kinship and the New Reproductive Technologies. Manchester: Manchester University Press.

Strathern, Marilyn. 1995. Displacing knowledge. Technology and the consequences for kinship. In Conceiving the New World Order. The Global Politics of 
Reproduction, edited by Faye D. Ginsburg and Rayna Rapp, 346-363. Berkeley:

University of California Press.

Strathern, Marilyn. 1999. Property, Substance and Effext: Anthropological Essays on Persons and Things. London: the Athlone Press.

Strathern, Marilyn. 2005. Kinship, Law and the Unexpected. Relatives Are Always a Surprise. Cambridge: Cambridge University Press.

Sullivan, Maureen. 2004. The Family of Woman: Lesbian Mothers, Their Children, and the Undoing of Gender. Berkeley: University of California Press.

Taylor, Yvette. 2009. Lesbian and Gay Parenting. Securing Social and Educational Capital. Basingstoke: Palgrave Macmillan.

Thompson, Charis. 2005. Making Parents. The Ontological Choreography of Reproductive Technologies. Cambridge, Massachusetts: MIT.

Weeks, Jeffrey, Heaphy, Brian and Catherine Donovan. 2001. Same Sex Intimacies:

Families of Choice and Other Life Experiments. New York: Routledge.

\footnotetext{
'By referring to 'Euro-American' kinship discourse I seek to map some of the fundamental dimensions of the kinship idioms shared within Europe and North America, notwithstanding the variations in gender and family discourse emerging on local, regional and national levels within and across the continents.

${ }^{i i}$ Five sites were selected for advertisement: www.gaydarnation.com, www.stonewall.org.uk, www.lgbtparents.proboards74.com, www.gingerbeer.co.uk, http://groups.msn.com/LesbianInseminationSupport.

iii The concept of donor anonymity changed in the UK in 2005 when donor identity release was implemented. Children conceived after 1 April 2005 are able to seek identifying information about their donors at 18.

iv These couples had to meet up with the donors to arrange retrieving sperm, and parental agreements stipulating a detached relationship were not legally binding.
} 